\title{
Structure and Function of Mammalian Ribosomes
}

\section{II. $\dagger$ Exchange of Ribosomal Subunits at Various Stages of in vitro Polypeptide Synthesis}

\author{
A. K. Falvey and T. Staehelin $\ddagger$ \\ Department of Zoology, University of Michigan \\ Ann Arbor, Michigan, U.S.A.
}

(Received 14 April 1970)

\begin{abstract}
(1) During in vitro polypeptide chain termination by rat or mouse liver polysomes, $80 \mathrm{~s}$ monosomes briefly dissociate into free subunits, presumably at the moment of their relase from the messenger. The subunits reassociate to form $80 \mathrm{~s}$ couples. In this reassociation step labeled $40 \mathrm{~s}$ subunits added to the incubation mixture freely compete with unlabeled subunits.

(2) The $80 \mathrm{~s}$ ribosomes reformed after termination of the polypeptide chain slowly exchange their subunits with radioactive subunits in the reaction mixture. The equilibrium between free subunits and $80 \mathrm{~s}$ couples strongly favors the latter.

(3) In contrast to polypeptide chain termination, at initiation of polyphenylalanine synthesis directed by polyuridylic acid, $80 \mathrm{~s}$ ribosomes attach to this messenger without a dissociation step.
\end{abstract}

\section{Introduction}

In this report we describe the behavior of mammalian ribosomal subunits during in vitro polypeptide synthesis. Specifically, we asked if $80 \mathrm{~s}$ couples dissociate and reassociate during protein synthesis, and if they do dissociate and reassociate, at which steps do these reactions occur. Our approach was to add radioactively labeled $40 \mathrm{~s}$ subunits to unlabeled ribosomes at various stages of polypeptide synthesis. If at any stage short dissociation followed by reassociation of the subunits occurs, the radioactive subunits added to the incubation mixture should compete in the reassociation reaction and, therefore, enter the reformed $80 \mathrm{~s}$ couples.

From these experiments we have found that during termination of protein synthesis and release of the polypeptide chain from the ribosome, the $80 \mathrm{~s}$ couple dissociates into $60 \mathrm{~s}$ and $40 \mathrm{~s}$ subunits which rapidly reassociate to form free $80 \mathrm{~s}$ monosomes. These reformed free $80 \mathrm{~s}$ couples continue to exchange their subunits with free 40 or $60 \mathrm{~s}$ subunits present in the incubation mixture; we call this reaction "post-termination exchange". The post-termination exchange rate is very slow. The dissociationreassociation equilibrium strongly favors the state of the $80 \mathrm{~s}$ species as evidenced from sucrose gradient analysis. The experiments described in this report also demonstrate that at initiation of poly U-directed polyphenylalanine synthesis, preformed

$\dagger$ Paper I in this series is Falvey \& Staehelin, 1970.

† Present address, and for reprints: Basel Institute for Immunology CH-4002 Basel, P.O. Box, Switzerland. 


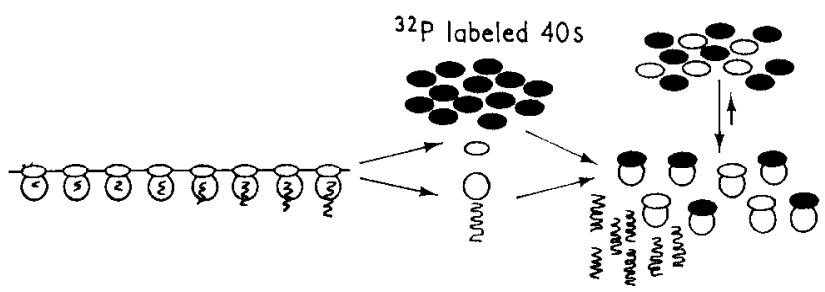

Termination

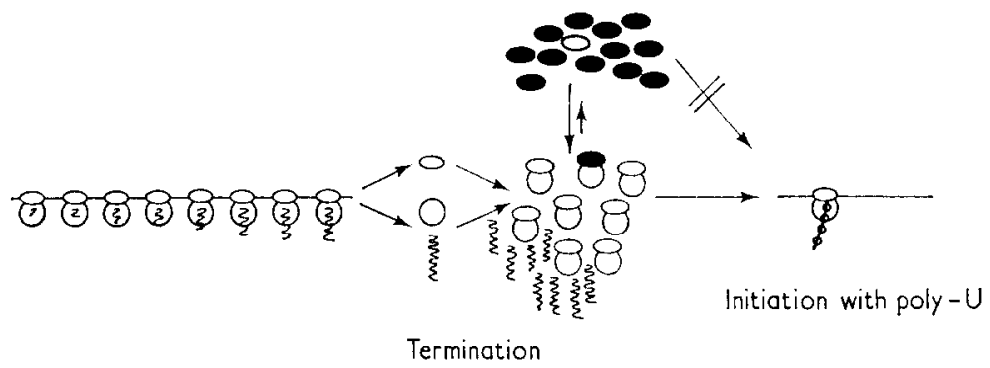

FIG. I. Illustration of experimental design and main implications of this study. Upper portion: ${ }^{32} \mathrm{P}$-labeled $40 \mathrm{~s}$ subunits were present during the incubation of polysomes in conditions supporting chain elongation and termination. Illustration of subunit exchange during polypeptide chain termination. Lower portion: ${ }^{32} \mathrm{P}$-labeled $40 \mathrm{~s}$ subunits added after preincubation of polysomes for polypeptide chain termination. Illustration of post-termination exchange and of poly $U$-dependent polypeptide chain initiation.

Single arrows indicate distinct steps. Bidirectional double arrows indicate equilibrium reactions.

$80 \mathrm{~s}$ couples attach to the messenger without prior dissociation into subunits. These results are schematically summarized in Figure. 1

\section{Materials and Methods}

(a) Preparation of radioactive ribosomal subunits

All methods for preparation and isolation of polysomes and subunits as well as $\mathrm{pH} 5$ enzyme and high speed supernatant are the same as described in the preceding peper (Falvey \& Staehelin, 1970). ${ }^{32} \mathrm{P}$-labeled subunits were prepared from mice which had been injected intraperitoneally with $1 \mathrm{mc}$ of carrier-free ${ }^{32} \mathrm{P}$-labeled $\mathrm{H}_{3} \mathrm{O}_{4}$ in $0 \cdot 15 \mathrm{M}$ - NaCl 18 to $20 \mathrm{hr}$ before exsanguination under ether anaesthesia. The purified ${ }^{32} \mathrm{P}$-labeled polysomes were exhaustively preincubated in a protein synthesizing system in order to terminate and release the polypeptide chains. The chilled roaction mixturo was made $0.5 \mathrm{~m}-\mathrm{KCl}$ and centrifuged in sucrose gradients containing $0.3 \mathrm{~m}-\mathrm{KCl}, 0.003 \mathrm{M}$-magnesium acetate, $0.02 \mathrm{M}$ Tris-HCl pH 7.5 and $0.001 \mathrm{M}$-dithiothreitol. The gradient fractions containing pure 40 and $60 \mathrm{~s}$ subunits were precipitated with ethanol (40\% final concentration). Figure 2 shows the analysis in low and high salt of purified ${ }^{32} \mathrm{P}-$ labeled $40 \mathrm{~s}$ subunits. The initial, specific activity of various preparations was between 12,000 and $16,000 \mathrm{cts} / \mathrm{min}$ per 0. D.260 unit of ribosomes.

\section{(b) Conditions for incubation}

(i) Experiments concerning subunit exchange during termination of polypeptide chains as well as "preincubation" of polysomes to obtain $80 \mathrm{~s}$ monosomes for post-termination and initiation exchange experiments

The reaction mixtures contained per $\mathrm{ml}: 1 \mu$ mole ATP, $0.4 \mu$ mole GTP, $10 \mu$ mole phosphocreatine, $40 \mu \mathrm{g}$ creatine phosphokinase, $0.2 \mathrm{ml}, \mathrm{S}_{100} \dagger, 0.2 \mathrm{ml}$. pH 5 enzyme, $150 \mu$ mole

$\uparrow$ Abbreviation used: $S_{100}$, high speed supernatant fraction. 


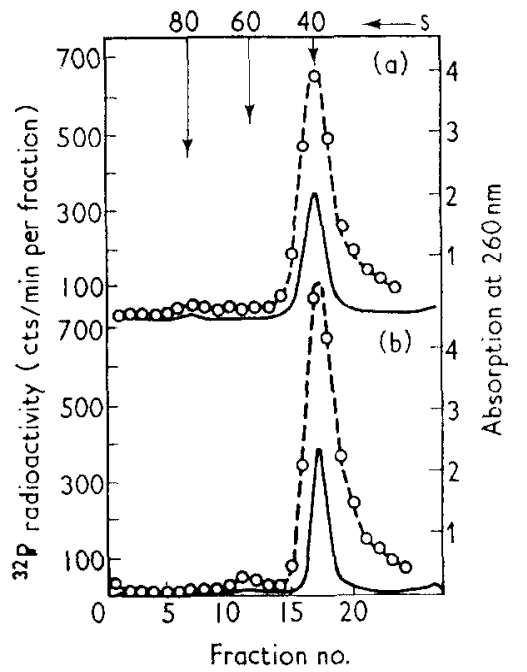

Frc. 2. Purified ${ }^{32}$ P-labeled $40 \mathrm{~s}$ subunits analyzed in low salt (a) and high salt (b) sucrose gradients. The asymmetry of the radioactivity is primarily due to the loss of resolution in the tubing between the ultraviolet absorption flow cell and the counting vial. In later experiments this was partially improved by eliminating a $\mathrm{U}$-turn in the tubing. - $\mathrm{O}--\mathrm{O}--,{ }^{32} \mathrm{P}$ radioactivity;

-

$\mathrm{NH}_{4} \mathrm{Cl}, 5 \mu$ mole magnesium acetate, $20 \mu$ mole Tris- $\mathrm{HCl} \mathrm{pH} 7 \cdot 5,1 \mu$ mole dithiothreitol, and polysomes (13 to 20 o.D.260 units depending on the experiment) and when specified $\left[{ }^{3} \mathrm{H}\right]$ phenylalanine with a specific activity of $6.3 \mathrm{c} / \mathrm{m} \cdot \mathrm{mole}$ (the amount used is specified in each corresponding Figure). The length of time and temperatures used for the incubations are indicated in each Figure.

(ii) Experiments concerning exchange at initiation with polyuridylic acid template (poly $U$ )

Following preincubation as described above, we added to the reaction mixtures per ml.: ${ }^{32}$ P-labeled $40 \mathrm{~s}$ subunits (amounts indicated in each Figure), 7 mole magnesium acetate (final concentration is $12 \mu \mathrm{mole} / \mathrm{ml}$.), $0.375 \mathrm{mg}$ poly $\mathrm{U},\left[{ }^{3} \mathrm{H}\right]$ phenylalanine with a specific activity of $6.3 \mathrm{c} / \mathrm{m}$-mole (amounts indicated in each Figure), $5 \mu$ mole phosphocreatine, and $20 \mu \mathrm{g}$ creatine phosphokinase. The reaction mixtures were incubated at $30^{\circ} \mathrm{C}$, for the lengths of time specified in each Figure.

\section{(c) Sucrose gradient analysis and radioactivity measurements}

All sucrose gradient analyses in this report were carried out using the SW 50.1 Spinco rotor at $50,000 \mathrm{rev} . / \mathrm{min}$ and $4^{\circ} \mathrm{C}$ for the times indicated in each Figure. Unless otherwise specified in the Figures, we used $5 \mathrm{ml}$. convex exponential gradients from 0.4 to $1.0 \mathrm{M}$ sucrose in which ribosomes sediment almost isokinetically throughout the gradient. After centrifugation, the absorption at $260 \mathrm{~nm}$ was monitored continuously and fractions collected directly into counting vials and counted in a Beckman LS250 liquid scintillation spectrometer as described in the preceding paper (Falvey \& Staehelin, 1970). In all Figures the optical density scales are corrected to a $1-\mathrm{cm}$ light path. In double label experiments with ${ }^{3} \mathrm{H}$ and ${ }^{32} \mathrm{P}$ the window discriminators for the two channels were set to give $0 \%$ of the ${ }^{3} \mathrm{H}$ counts in the ${ }^{32} \mathrm{P}$ window and $8 \%{ }^{32} \mathrm{P}$ counts in the ${ }^{3} \mathrm{H}$ window. At these settings the counting efficiency of ${ }^{32} \mathrm{P}$ was $80 \%$ and that of ${ }^{3} \mathrm{H}$ was $16 \%$.

\section{(d) Analysis of in vitro subunit exchange}

\section{(i) During polypeptide chain termination}

Reaction mixtures containing polysomes and ${ }^{32} \mathrm{P}$-labeled $40 \mathrm{~s}$ subunits plus all the components required for polypeptide synthesis were incubated at $25^{\circ} \mathrm{C}$ for various lengths of time, then chilled and analyzed by sucrose gradient centrifugation in low salt ionic 
conditions ( $0 \cdot 1 \mathrm{M}-\mathrm{NH}_{4} \mathrm{Cl}$ and $0.005 \mathrm{M}$-magnesium acetate). The concentration of polysomes was chosen to result in a suitable amount of $80 \mathrm{~s}$ monosomes released afler a given lime of incubation. The amount of radioactive $40 \mathrm{~s}$ subunits was chosen to result in a ratio of free $80 \mathrm{~s}$ monosomes to $40 \mathrm{~s}$ subunits feasible for radioactivity analysis of the gradients. This ratio was varied on purpose in different experiments by a factor of at least 2.5 in order to assure that the degree of subunit exchange was independent of this ratio.

\section{(ii) After termination}

Reaction mixtures containing unlabeled polysomes were incubated at $30^{\circ} \mathrm{C}$ to allow complete polypeptide chain termination and release of $80 \mathrm{~s}$ couples from mRNA. Then radioactive $40 \mathrm{~s}$ subunits were added and the incubation was continued in the same ionic conditions for the specified lengths of time followed by sucrose gradient analysis in low salt conditions.

\section{(iii) During poly $U$-directed polypeptide chain initiation}

After preincubation of polysomes to allow complete chain termination, we added to the reaction mixture in the following order at $0^{\circ} \mathrm{C}:{ }^{32} \mathrm{P}$-labeled $40 \mathrm{~s}$ subunits, $\left[{ }^{3} \mathrm{H}\right]$ phenylalanine, poly U, magnesium acetate, phosphocreatine, and creatine phosphokinase in concentrations as specified above. The reaction mixtures were then incubated at $30^{\circ} \mathrm{C}$ for specified lengths of time, after which they were centrifuged through sucrose gradients containing high salt ( $0.3 \mathrm{M}-\mathrm{KCl}$ and $0.003 \mathrm{M}$-magnesium acetate). These ionic conditions allow selective analysis of $80 \mathrm{~s}$ ribosomes which have initiated polypeptide synthesis with poly $U$.

\section{Results}

\section{(a) Subunit exchange during polypeptide chain termination}

Since there is negligible reinitiation in our in vitro system for protein synthesis using purified liver polysomes, polypeptide chain elongation and termination are the two main processes which occur during incubation. At termination $80 \mathrm{~s}$ monosomes are released from the messenger and accumulate. In order to study the fate of the ribosomal subunits during termination, at zero time we added different amounts of radio. actively labeled $40 \mathrm{~s}$ subunits to the reaction mixtures which we then incubated at $25^{\circ} \mathrm{C}$ for various lengths of time. Figure 3 shows sucrose gradient analyses of the reaction mixtures. $80 \mathrm{~s}$ monosomes and 60 and $40 \mathrm{~s}$ subunits are separated and displayed in the gradient while the remaining polysomes have pelleted. It is clear that radioactive $40 \mathrm{~s}$ subunits did enter the $80 \mathrm{~s}$ ribosomes which accumulated during each incubation period. The pronounced broadening and trailing of the radioactivity behind the $80 \mathrm{~s}$ optical density peak, due to some mixing of the more shallow lower part of the gradients in the collecting system, makes a visual estimate of the degree of subunit exchange unfeasible. But from the integrated optical density and radioactivity peak areas we can calculate that during each incubation period the subunits in the accumulated $80 \mathrm{~s}$ particles had almost completely equilibrated with free radioactive subunits (for details see Results section (d)). In Figure 4 the sucrose gradients display polysomes, released $80 \mathrm{~s}$ ribosomes and free subunits from incubation mixtures in which the polypeptide chains are labeled with $\left[{ }^{3} \mathrm{H}\right]$ phenylalanine. This experiment clearly shows that radioactive $40 \mathrm{~s}$ subunits exchange with those of released $80 \mathrm{~s}$ couples but not with polysomes; thus, dissociation and reassociation of subunits must occur at or after termination. Again, after both five and ten minutes of incubation, the subunits of the $80 \mathrm{~s}$ ribosomes have almost completely equilibrated with the free radioactive $40 \mathrm{~s}$ subunits. The absence of any significant quantity of ${ }^{32} \mathrm{P}$-radioactivity in the polysomes, even after ten minutes of incubation, demonstrates that no appreciable reattachment of ribosomes to polysome-associated mRNA occurs. Furthermore, the 


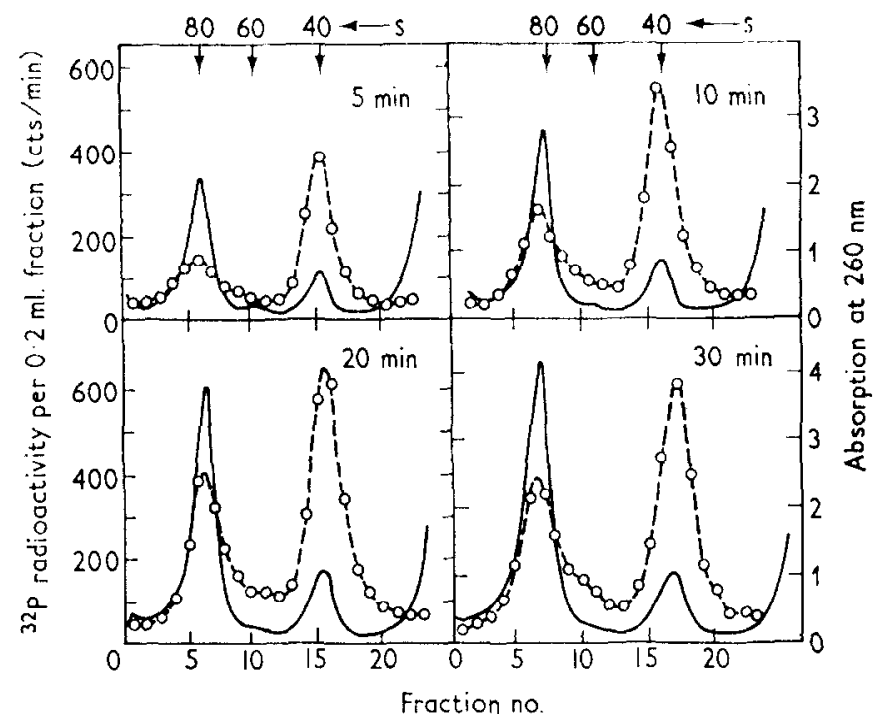

Fia. 3. Exchange of ribosomal subunits during polypeptide chain termination. $0.3-\mathrm{ml}$. samples of reaction mixture were ineubated at $25^{\circ} \mathrm{C}$ for the indicated lengths of time. Following the incubation the reaction mixtures were chilled and immediately layered onto $5-\mathrm{ml}$. low salt sucrose gradients which were centrifuged at $4^{\circ} \mathrm{C}$ for $2 \mathrm{hr}$ at $50,000 \mathrm{rev} . / \mathrm{min}$. The reaction mixtures contained the following amounts of polysomes and ${ }^{32} \mathrm{P}$-labeled $40 \mathrm{~s}$ subunits: 5-min incubation, 6 o.D.280 units of polysomes and 0.26 O.D.260 unit of ${ }^{32} \mathrm{P}$-labeled $40 \mathrm{~s}$ subunits; 10 -min incubation, 5 O.D.260 units of polysomes and $0.40 \mathrm{O}$.D.260 unit of ${ }^{32} \mathrm{P}$-labeled $40 \mathrm{~s}$ subunits; 20 -min incubation, 4 O.D.260 units of polysomes and 0.55 o.D.260 unit of ${ }^{32} \mathrm{P}$-labeled $40 \mathrm{~s}$ subunits; 30 -min incubation, 3 o.D.260 units of polysomes and 0.55 O.D.260 unit of ${ }^{32} \mathrm{P}$.labeled $40 \mathrm{~s}$ subunits. $--\mathrm{O}_{--} \mathrm{O}_{--},{ }^{32} \mathrm{P}$ radioactivity, —_ absorbance at $260 \mathrm{~nm}$.

lack of $\left[{ }^{3} \mathrm{H}\right]$ phenylalanine radioactivity in the $80 \mathrm{~s}$ region shows that most of the polypeptide chains are released from the $80 \mathrm{~s}$ particles.

\section{(b) Post-termination subunit exchange}

From the experiments described above we cannot distinguish whether subunit exchange (that is, dissociation and reassociation) is coupled to, and therefore a direct result of, the termination event or whether subunit exchange occurs very rapidly after termination. In order to distinguish between these two possibilities, we wanted to determine the rate of possible subunit exchange in the absence of polypeptide chain termination. In these experiments we incubated polysomes under conditions for protein synthesis long enough to ensure polypeptide chain termination by all competent ribosomes and then added ${ }^{32}$ P-labeled $40 \mathrm{~s}$ subunits to the reaction mixture which we further incubated for various lengths of time. Sucrose gradient analyses of these reaction mixtures demonstrate that labeled $40 \mathrm{~s}$ subunits do exchange with the $40 \mathrm{~s}$ subunits of the $80 \mathrm{~s}$ couples. Figure 5 shows the kinetics of this post-termination exchange in ionic conditions identical to those used for protein synthesis with endogenous mRNA (0.15 $\mathrm{M}-\mathrm{NH}_{4} \mathrm{Cl}$ and $0.005 \mathrm{~m}$ magnesium acetate). The exchange is, however, very slow and does not reach equilibrium even after 50 minutes of incubation. This is most evident from a comparison between Figure 5 and the 30-minute incubation of Figure 3 ; all of these sucrose gradients contain about the same ratio of $80 \mathrm{~s}$ to free $40 \mathrm{~s}$ particles. 


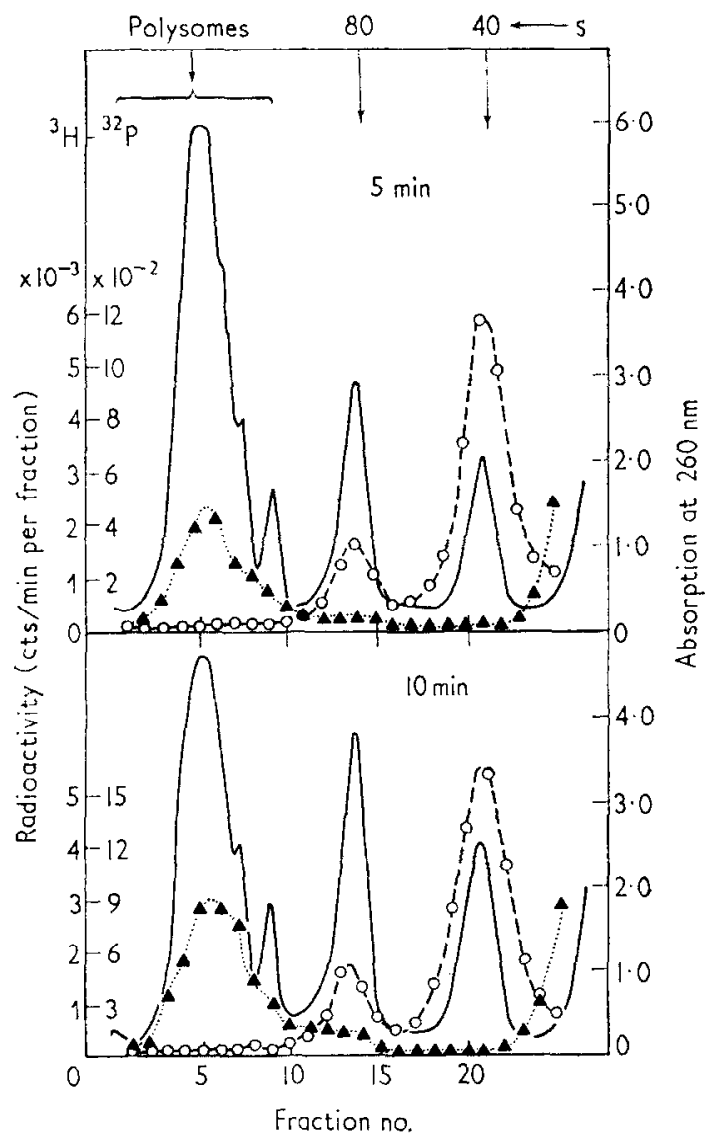

F'ra. 4. Exchange of ribosomal subunits during polypeptide ehain termination exclusively between released $80 \mathrm{~s}$ couples and free subunits. Incubations were carried out as described in Fig. 3 with the following modifications: (1) $0.3 \mathrm{ml}$. of the reaction mixture contained $1.4 \mu \mathrm{C}\left[{ }^{3} \mathrm{H}\right] \mathrm{phenyl}$ alanine to label the nascent protein chains; (2) the 5 -min incubation contained per $0 \cdot 3 \mathrm{ml} .6$ O.D.260 units of polysomes and 0.8 o.D.260 unit of ${ }^{32} \mathrm{P}$-labeled $40 \mathrm{~s}$ subunits and the $10-\mathrm{min}$ incubation contained per $0.3 \mathrm{ml} .5$ O.D.260 units of polysomes and 1.2 o.D.280 units of ${ }^{32}$ P.labeled $40 \mathrm{~s}$ subunits. These reaction mixtures were analyzed in low salt sucrose gradients which consisted of $0.7 \mathrm{ml}$. of a $2 \mathrm{M}$-sucrose cushion, $0.8 \mathrm{ml}$. of a manually layered gradient from 1.8 to $1.2 \mathrm{M}$-sucrose, and $3.5 \mathrm{ml}$. of a continuous convex gradient from 0.4 to $1.0 \mathrm{M}$-sucrose, (These gradients were prepared 4 to $5 \mathrm{hr}$ before use.) Centrifugation was for $80 \mathrm{~min}$ at $50,000 \mathrm{rev} . / \mathrm{min}$ and $4^{\circ} \mathrm{C}$. Polysomes accumulate at the very steep lower part of the gradient whereas $80 \mathrm{~s}$ ribosomes and subunits are well separated in the flatter upper part of the gradients.

A possible source of error in the interpretation of the experiments concerning the subunit exchange during or after termination may lie in the fact that as termination proceeds, the amount of free $80 \mathrm{~s}$ ribosomes constantly increases from almost zero to the amount present at the end of the incubation period. On the other hand, during the post-termination exchange experiments shown in Figure 5, the ratio of $80 \mathrm{~s}$ ribosomes to labeled $40 \mathrm{~s}$ subunits was constant throughout the entire incubation period. Therefore, we did post-termination exchange experiments in which we mimicked as closely as possible the kinetics of $80 \mathrm{~s}$ accumulation observed in the termination experiments. To an incubation mixture containing labeled $40 \mathrm{~s}$ subunits post-termination $80 \mathrm{~s}$ ribosomes were added in small increments at short intervals throughout the incubation 


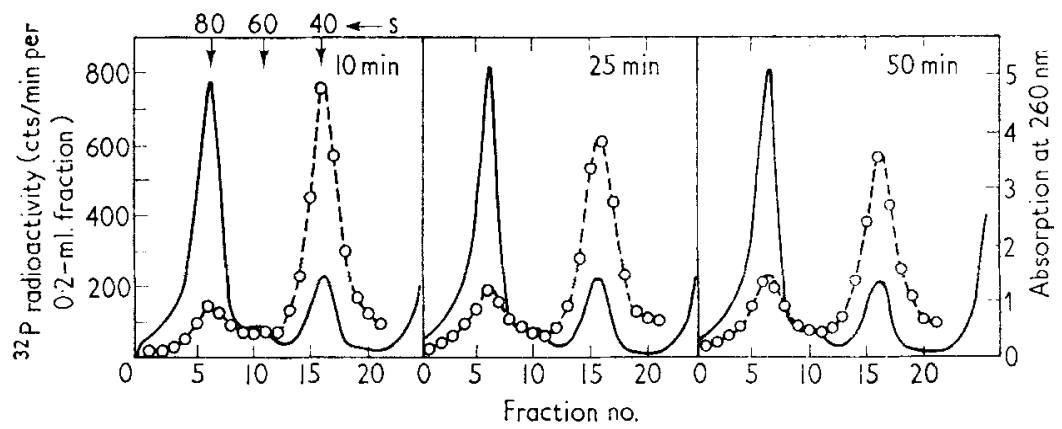

FIG. 5. Kinetics of post-termination exchange. 10 o.D.260 units of polysomes per ml. were preincubated as described in Materials and Methods to allow completo polypoptido chain tormination. 3.7 0.D.260 units of ${ }^{32} \mathrm{P}$-labeled $40 \mathrm{~s}$ subunits per ml. were then added and incubation was continued at $25^{\circ} \mathrm{C}$ for 10,25 and $50 \mathrm{~min} .0 \cdot 2-\mathrm{ml}$. samples of the reaction mixtures wore immediately centrifuged in $5 \mathrm{ml}$. low salt sucrose gradients at $4^{\circ} \mathrm{C}$ for $2 \mathrm{hr}$ at $50,000 \mathrm{rov} / \mathrm{min} .--\mathrm{O}_{--}-\mathrm{O}_{-}$, ${ }^{32} \mathrm{P}$ radioactivity; - absorbance at $260 \mathrm{~nm}$.

period. The results (not shown here) demonstrate that the degree of exchange after 5 and 20 minutes is indistinguishable from that observed when all of the $80 \mathrm{~s}$ ribosomes were present from the beginning of the incubation. Thus, the striking difference in the extent of subunit equilibration between termination and post-termination exchange experiments cannot be attributed to the variation in the ratio of $80 \mathrm{~s}$ to labeled $40 \mathrm{~s}$ particles.

The experiments described so far illustrate that $80 \mathrm{~s}$ ribosomes briefly dissociate into free subunits and reassociate to form $80 \mathrm{~s}$ couples upon their release from polysomes at termination of the polypeptide chain. In the reassociation step free subunits (such as radioactive $40 \mathrm{~s}$ subunits) which are present in the incubation mixture compete with the polysome-derived $40 \mathrm{~s}$ subunits. After this distinct dissociation and reassociation, the $80 \mathrm{~s}$ couples remain in an equilibrium with free subunits. But the rate of subunit exchange occurring after termination is very slow; and the equilibrium strongly favors the state of 80 s couples.

In additional control experiments we degraded polysomes by treatment with pancreatic ribonuclease (RNase) into monosomes which are as stable in high salt as undegraded polysomes. As expected these $80 \mathrm{~s}$ ribosomes do not exchange subunits with radioactive $40 \mathrm{~s}$ subunits in ionic conditions where post-termination subunit exchange oceirs.

\section{(c) Lack of subunit exchange during polyphenylalanine chain initiation}

Like chain termination, when 80 s ribosomes are released from mRNA, polypeptide chain initiation is a distinct and specific mechanism in protein synthesis. We therefore wanted to determine whether the step of ribosome attachment to mRNA and polypeptide chain initiation is preceded by an obligatory dissociation of $80 \mathrm{~s}$ ribosomes into subunits, or whether the ribosomes must initiate as an $80 \mathrm{~s}$ couple. At this time, for lack of availability of natural mRNA, we are restricted to the use of an artificial template, namely poly $\mathrm{U}$. We are aware of the inherent limitations of this system.

To a reaction mixture containing free $80 \mathrm{~s}$ ribosomes formed during exhaustive incubation of polysomes in a complete system, we added at $0^{\circ} \mathrm{C}$ in the following order: ${ }^{32} \mathrm{P}$-labeled $40 \mathrm{~s}$ subunits, $\left[{ }^{3} \mathrm{H}\right]$ phenylalanine, and poly $\mathrm{U}$ plus other components to 


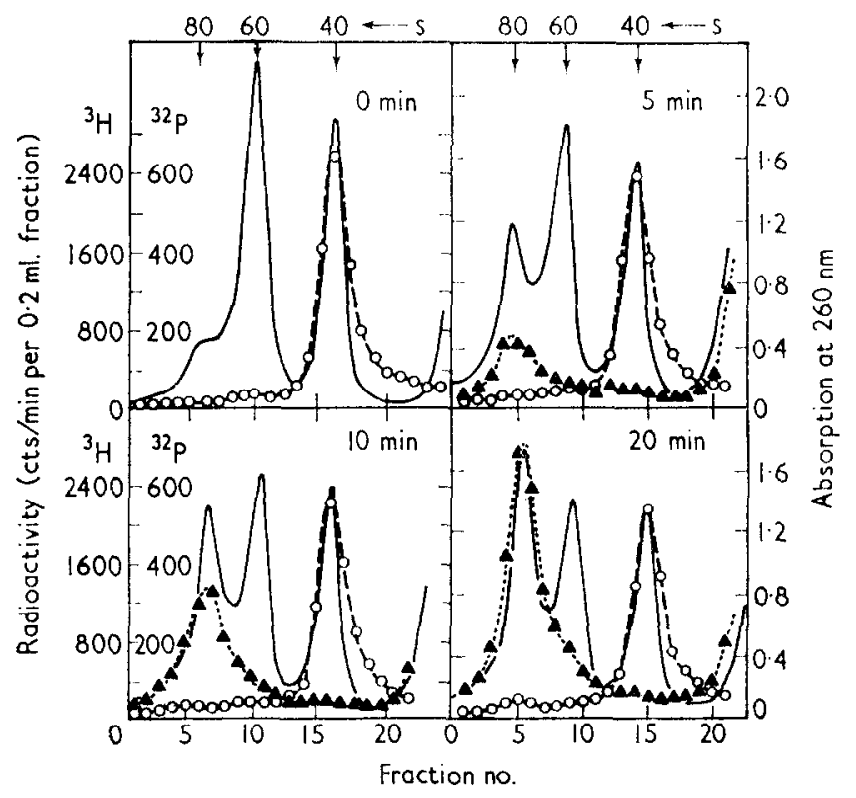

Frg. 6. Absence of subunit exchange during initiation of poly U-directed polyphenylulanine synthesis. After preincubation of polysomes as described in Materials and Methods to allow termination of endogenous protein synthesis, the following components were added in the listed order to each ml. chilled reaction mixture: 2 o.D.260 units of ${ }^{32}$ P-labeled $40 \mathrm{~s}$ subunits, $2 \cdot 3 \mu \mathrm{C}$ $\left[{ }^{3} \mathrm{H}\right]$ phenylalanine $(6 \cdot 3 \mathrm{c}$ per $\mathrm{m}$-mole), $0.375 \mathrm{mg}$ poly $\mathrm{U}, 7 \mu$ moles magnesium acetate, $5 \mu \mathrm{moles}$ phosphocreatine and $20 \mu \mathrm{g}$ creatine phosphokinase. Incubation was then continued at $30^{\circ} \mathrm{C}$ for $0,5,10$ and $20 \mathrm{~min}$ following which the reaction mixtures were chilled in ice and made $0.5 \mathrm{M}-\mathrm{KCl}$. Immodiatoly $0 \cdot 2-\mathrm{ml}$ samplos woro layered onto high salt sucrose gradients and centrifuged at $4^{\circ} \mathrm{C}$ for $2 \mathrm{hr}$ at $50,000 \mathrm{rev} . / \mathrm{min}$ and then analyzed as described in Materials and Methods.

adjust the system to conditions needed for polyphenylalanine synthesis. Following incubation at $30^{\circ} \mathrm{C}$ for $0,5,10$ and 20 minutes, we made the reaction mixtures $0.5 \mathrm{M}$ $\mathrm{KCl}$ and analyzed them in sucrose density gradients containing $0.3 \mathrm{~m}-\mathrm{KCl}$ and 0.003 M-magnesium acetate. In these conditions only the active poly U-peptidyltRNA-ribosome complexes sediment as stable 80 s particles, while the remaining free ribosomes dissociate into subunits. Such an experiment is shown in Figure 6. Without incubation only the small fraction of ribosomes which did not terminate during the preincubation sediment as "stuck" 80 s particles. After 5,10 and 20 minutes of incubation, the amounts of stable $80 \mathrm{~s}$ ribosomes carrying labeled polyphenylalanine increased, but they contain almost no radinactive $40 \mathrm{~s}$ subunits. The small amount of ${ }^{32} \mathrm{P}$-labeled $40 \mathrm{~s}$ subunits which sediment in stable $80 \mathrm{~s}$ couples can be accounted for by post-termination exchange occurring before initiation. We measured the rate of this exchange in the absence of poly $U$ but in the sume ionic conditions. It is considerably slower than the post-termination exchange at the lower magnesium ion concentrations used for protein synthesis directed by endogenous messenger. (See Fig. 8 which is a summary of all exchange experiments.)

One might still argue that the preferential exclusion of radioactive $40 \mathrm{~s}$ subunits in polyphenylalanine synthesis is due to a much lower activity of these purified subunits compared to the polysome-derived $80 \mathrm{~s}$ ribosomes. In order to test this possibility, the 
$80 \mathrm{~s}$ ribosomes to be used in polyphenylalanine synthesis were formed by preincubation of polysomes in the presence of purified ${ }^{32} \mathrm{P}$-labeled $40 \mathrm{~s}$ subunits. Then, after addition of $\left[{ }^{3} \mathrm{H}\right]$ phenylalanine and poly $\mathrm{U}$, we further incubated the reaction mixture in conditions suitable for polyphenylalanine synthesis. Figure $7(a)$ shows that ${ }^{32} \mathrm{P}$-labeled $40 \mathrm{~s}$ subunits completely equilibrated with unlabeled polysome-derived $40 \mathrm{~s}$ subunits

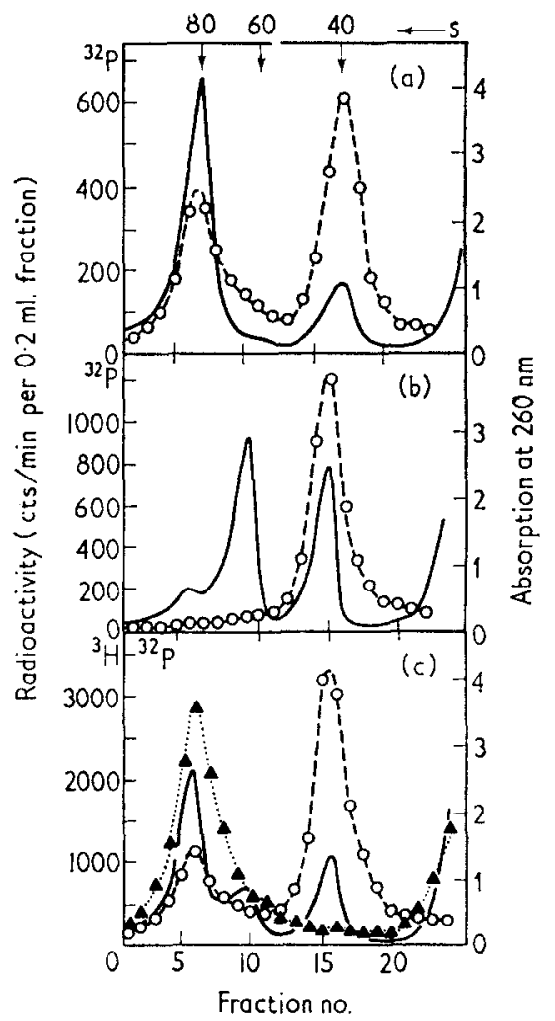

Fia. 7. Exchange of ${ }^{32} \mathrm{P}$-labeled $40 \mathrm{~s}$ subunits into $80 \mathrm{~s}$ ribusomes during polypetide chain termination and subsequent participation in poly $U$-directed polyphenylalanine synthesis. (a) Low salt sucrose gradient analysis after completion of chain termination. (b) High salt sucrose gradient analysis of the same reaction mixture as in (a). (c) Iligh salt sucrose gradient analysis of a similar reaction mixture after further incubation for $30 \mathrm{~min}$ in the presence of poly $\mathrm{U}$ and $\left[{ }^{3} \mathrm{H}\right] \mathrm{phenyl-}$ alanine in conditions for polyphenylalanine synthesis. Note the contracted scale of ${ }^{32} P$ radioactivity in (b). - Absorbance at $260 \mathrm{~nm}$.

upon chain termination. Analysis of the same incubation mixture in high salt demon$\mathrm{s}$ trates that no measurable $40 \mathrm{~s}$ subunits remain in stable $80 \mathrm{~s}$ ribosomes (Fig. $7(\mathrm{~b})$ ). However, after poly U-directed polyphenylalanine synthesis, a large fraction of ribosomes is now found as high salt stable active $80 \mathrm{~s}$ complexes (Fig. 7(c)) which contain about the same proportion of ${ }^{32} \mathrm{P}$-labeled $40 \mathrm{~s}$ subunits as the $80 \mathrm{~s}$ ribosomes contained before initiation. This clearly demonstrates that the added ${ }^{32} \mathrm{P}$-labeled $40 \mathrm{~s}$ subunits are about equally competent in polyphenylalanine synthesis as those in the polysomederived $80 \mathrm{~s}$ (with which they exchange during termination). Therefore, the lack of subunit exchange during poly U-directed polypeptide chain initiation is due to the fact that ribosomes initiate as $80 \mathrm{~s}$ couples with poly $\mathrm{U}$ template. 


\section{(d) Comparison of the rates of subunit exchange during various stages of protein synthesis}

Figure 8 summarizes the results of all subunit exchange experiments. The degree of subunit exchange as "percentage of full equilibration" was calculated in the following way: The optical density (O.D. at $260 \mathrm{~nm}$ ) of the $80 \mathrm{~s}$ peak was integrated and divided by 3.7 in order to compute the amount of $40 \mathrm{~s}$ subunits present in the $80 \mathrm{~s}$ peak

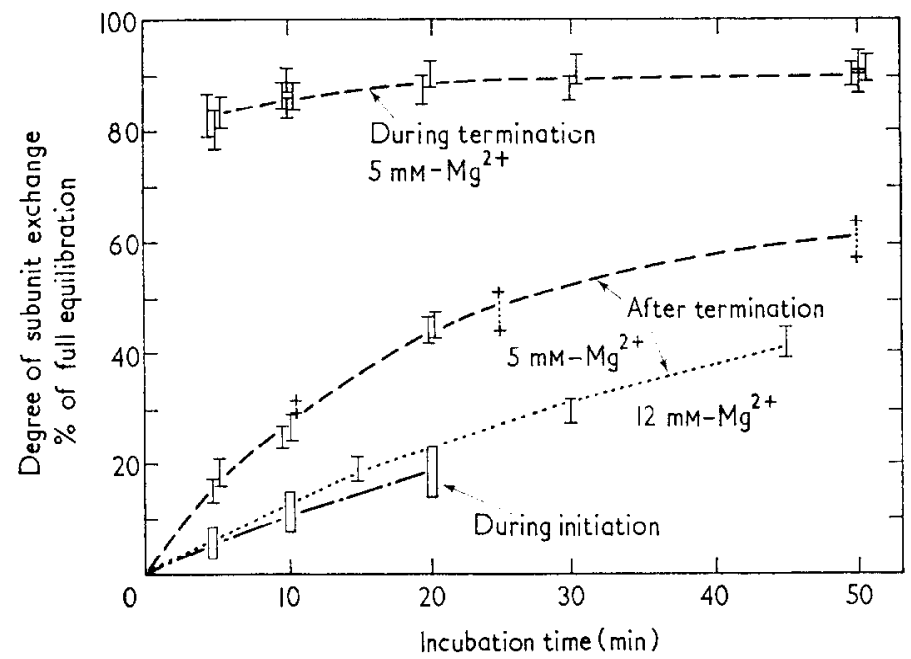

FIG. 8. Summary of data from experiments concerning subunit exchange at polypeptide chain termination, post-termination, and polyphenylalanine chain initiation. The degree of subunit exchange as percentage of full equilibration between radioactive and non-radioactive subunits in the $80 \mathrm{~s}$ particles was calculated as decribed in the text. Each solid bar represents the data from one sucrose gradient analysis. Each of the open bars showing the subunit exchange during initiation of polyphenylalanine synthesis represents the data from two independent experiments. The crosses connected by dotted lines represent the experiment shown in Fig. 5.

(designated $[40]_{80}$ ). The factor $3 \cdot 7$ reflects a 60 to $40 \mathrm{~s}$ subunit RNA mass ratio of $2 \cdot 7: 1$. The amount of free $40 \mathrm{~s}$ subunits are designated $[40]_{40}$. The amounts of radioactivity in the $80 \mathrm{~s}$ peak and $40 \mathrm{~s}$ peak are designated $\left[\mathrm{P}^{32}\right]_{80}$ and $\left[\mathrm{P}^{32}\right]_{40}$ respectively. From these values we calculate the degree of exchange by dividing the fraction of the total radioactivity present in the $80 \mathrm{~s}$ peak by the fraction of the total $40 \mathrm{~s}$ mass present in the $80 \mathrm{~s}$ peak. Thus, the degree of exchange as percentage of full equilibration equals

$$
\frac{\left[{ }^{32} \mathrm{P}\right]_{80}}{\left[{ }^{32} \mathrm{P}\right]_{80}+\left[{ }^{32} \mathrm{P}\right]_{40}} \div \frac{[40]_{80}}{[40]_{80}+[40]_{40}} \times 100
$$

Full equilibration (exchange) between labeled and unlabeled subunits has occurred if the mass fraction of $40 \mathrm{~s}$ ribosomes found in the $80 \mathrm{~s}$ peak equals the fraction of the total radioactivity present in that peak.

Between 80 and $90 \%$ of full equilibration is attained at all times during the termination experiments. After very brief incubations ( 5 and $10 \mathrm{~min}$ ), the percentage of exchange was slightly lower, most likely resulting from the presence of some $80 \mathrm{~s}$ ribosomes in the original polysome preparation. These $80 \mathrm{~s}$ monosomes are high salt labile and therefore messenger-free couples which participate in the much slower posttermination exchange. In contrast to the instant subunit exchange occurring at polypeptide chain termination, the subunits of free $80 \mathrm{~s}$ ribosomes equilibrate very slowly 
with subunits present in the reaction mixture. Increasing the magnesium ion concentration of the medium results in even slower rates of post-termination (subunit) exchange in spite of the fact that the temperature for incubation was increased 5 $\mathrm{C}$ degrees $\left(\right.$ to $30^{\circ} \mathrm{C}$ ). This experiment was done to determine the rate of post-termination exchange in conditions of poly U-directed polypeptide chain initiation. During initiation of polyphenylalanine synthesis, very little subunit exchange occurs. The small amount of labeled $40 \mathrm{~s}$ subunits found in the stable $80 \mathrm{~s}$ ribosomes can be accounted for by the slow exchange occurring before $80 \mathrm{~s}$ couples initiate and become stabilized in the active complex of polypeptide synthesis.

\section{Discussion}

It has been well established for bacteria (Kaempfer, Meselson \& Raskas, 1968; Kaempfer, 1968) and at least one eucaryotic organism, yeast (Kaempfer, 1969), that the two ribosomal subunits making up the particle active in protein synthesis are not permanently associated. For Escherichia coli, Mangiarotti \& Schlessinger (1966) first suggested that ribosomes not engaged in protein synthesis exist as a pool of 30 and $50 \mathrm{~s}$ subunits which only combine to form stable $70 \mathrm{~s}$ couples associated with mRNA at the time of polypeptide chain initiation. At polypeptide chain termination the subunits are thought to dissociate and enter the pool of free subunits. Kaempfer et al. (1968) presented evidence for this model of ribosome cycling. They demonstrated with the use of heavy isotope labeling experiments that in growing bacteria the 30 and $50 \mathrm{~s}$ subunits found in polysome-derived $70 \mathrm{~s}$ particles exchange partners. And, extending this work to protein synthesis in vitro Kaempfer (1968) showed that when crude extracts from unlabeled and heavy isotope labeled bacteria were mixed under conditions supporting protein synthesis with endogenous mRNA, heavy and light subunits rapidly exchanged resulting in the formation of hybrid $70 \mathrm{~s}$ couples. The kinetics of this exchange were compatible with an exchange of subunits for each round of protein synthesis; thus, the subunits are at least temporarily, if not permanently, dissociated between chain termination and initiation. In an in vitro system with bacteriophage RNA as template Grubmann \& Nakada (1969) also found that $70 \mathrm{~s}$ ribosomes dissociate into subunits before they reinitiate a new polypeptide chain. Furthermore, in vitro experiments on polypeptide chain initiation with viral mRNA or polyribonucleotides containing the initiation codon $A U G$, suggest that natural chain initiation with formylmethionyl-tRNA involves first the formation of a $30 \mathrm{~s}-\mathrm{mRNA}$ complex. Fmet-tRNA is then bound to this complex followed by the joining of the $50 \mathrm{~s}$ subunit which results in the formation of the $70 \mathrm{~s}$ complex required for polypeptide synthesis. (Ghosh \& Khorana, 1967; Guthrie \& Nomura, 1968; Nomura, Lowry \& Guthrie, 1967; Nomura \& Lowry, 1967; Pestka \& Nirenberg, 1966). At the present time the most important features of the model of the ribosome cycle in bacteria are: (1) after termination of a polypeptide chain the $70 \mathrm{~s}$ ribosome couple dissociates into its subunits, and (2) the mechanism of polypeptide chain initiation involves the formation of the mRNA-ribosome complex from free 30 and $50 \mathrm{~s}$ subunits joining in a sequence rather than the joining of a preformed $70 \mathrm{~s}$ couple to the mRNA in a single step.

In ionic conditions used for in vitro protein synthesis, the high affinity between 40 and $60 \mathrm{~s}$ subunits of mammalian ribosomes makes the free $80 \mathrm{~s}$ couple the predominant and almost exclusive state of mRNA-free ribosomes. Analysis of incubation mixtures in sucrose gradients at 28 to $29^{\circ} \mathrm{C}$ demonstrates that even at this temperature 
free $80 \mathrm{~s}$ ribosomes are stable. If anything, we actually observed a smaller fraction of subunits in these gradients when compared with those analyzed at 2 to $4^{\circ} \mathrm{C}$. Therefore, dissociation of free $80 \mathrm{~s}$ ribosomes into subunits could be either a rare fortuitous event or a quickly reversible specific step in the mechanism of protein synthesis.

In our present study we demonstrate clearly the following events in the cycle of protein synthesis. (a) During polypeptide chain termination there is a specific dissociation step of the $80 \mathrm{~s}$ ribosomes into subunits followed immediately by reassociation of the free subunits to couples. We visualize the dissociation as the result of an obligatory conformational change of the ribosomes during the mechanism of polypeptide chain termination and release, probably coupled to ribosome disengagement from mRNA. (b) After polypeptide chain termination the dissociation and reassociaton of a free $80 \mathrm{~s}$ couple is a very rare event. (c) Poly U-directed polypeptide chain initiation occurs through the attachment of an $80 \mathrm{~s}$ couple and not of free subunits to the template.

The absence of a distinct dissociation step before initiation with poly $\mathrm{U}$ is an interesting observation since it is in contrast to the mechanism of natural initiation in bacterial systems. Yet, this does not allow us to make any predictions concerning natural chain initiation in mammalian protein synthesis. Quite likely mammalian protein synthesis also requires several initiation factors, one of which might induce and maintain subunit dissociation similar to the mechanism suggested by Subramanian, Ron \& Davis (1968) in $E$. coli. If mammalian polypeptide chain initiation is similar to that in bacteria, requiring free subunits for the formation of the active mRNAribosome complex, we would predict that one of the initiation factors causes ribosome dissociation by binding to one of the subunits (probably the $40 \mathrm{~s}$ subunit). Two types of observations in the literature suggest that free subunits rather than $80 \mathrm{~s}$ couples are competent in polypeptide chain initiation with natural messenger. Bishop (1966) observed that reticulocyte ribosome fractions rich in free 60 and $40 \mathrm{~s}$ sub. units are most active in hemoglobin chain initiation in vitro. In intact reticulocytes Colombo, Vesco \& Baglioni (1968) observed that NaF seemed to inhibit protein synthesis by interfering with ribosome dissociation. Thus, free subunits disappear during $\mathrm{NaF}$ treatment and reappear only during the recovery of the cells from $\mathrm{NaF}$. And, Girard, Latham, Penman \& Darnell (1965) and Hogan \& Korner (1968b) showed that in tissue-culture cells free 40 and $60 \mathrm{~s}$ subunits become rapidly labeled. These newly synthesized labeled subunits first enter polysomes and appear in the free $80 \mathrm{~s}$ pool at a much slower rate. It seems then that at least part of the large amount of $80 \mathrm{~s}$ particles often found in animal cells represents a special pool of ribosomes which do not participate in protein synthesis. Yet, it is has been shown that these $80 \mathrm{~s}$ ribosomes in vivo can be activated to participate in protein synthesis as polysomes. For instance, force feeding starved animals a complete amino-acid mixture (Baliga, Pronczuk \& Munro, 1968; Staehelin, Verney \& Sidransky, 1967) or transferring ascites tumor cells from an amino-acid-poor into an amino-acid-rich medium (Hogan $\&$ Korner, 1968a) causes a rapid decrease of $80 \mathrm{~s}$ monosomes concomitant with an increase of polysome mass and size, even if mRNA synthesis has been blocked by actinomycin $D$. It appears therefore that in animal cells a regulatory mechanism may reversibly inactivate the $80 \mathrm{~s}$ ribosomes thereby enabling the cell to adjust its over-all rate of protein synthesis to changing physiological conditions.

In order to test the possibility that in vivo $80 \mathrm{~s}$ ribosomes differ functionally from polysome-derived $80 \mathrm{~s}$ particles, we compared the competence in poly U-directed 


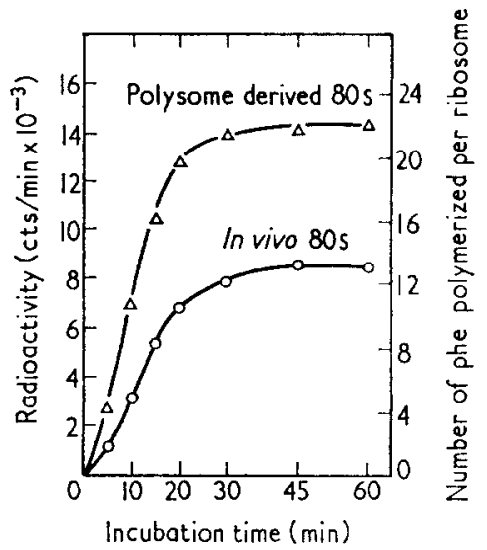

Fra. 9. Comparison of the kinetics of phenylalanine incorporation by polysome-derived and in vivo $80 \mathrm{~s}$ ribosomes. In vivo $80 \mathrm{~s}$ ribosomes were purified by sucrose gradient centrifugation of the postmitochondrial supernatant from mouse livers. Polysome.derived $80 \mathrm{~s}$ ribosomes prepared by incubation of purified polysomes in a protein synthesizing system were also isolated from sucrose gradients. The $80 \mathrm{~s}$ ribosomes in the sucrose gradient fractions were concentrated by alcohol precipitation and dissolved in low salt buffer. Reaction mixtures containing 7 o.D.260 units of ribosomes per ml. were incubated at $33^{\circ} \mathrm{C}$ in a complete poly $\mathrm{U}$ system as described in Materials and Methods. At various times 0.1-ml. portions were withdrawn and prepared for radioactivity counting as described in Materials and Mothods.

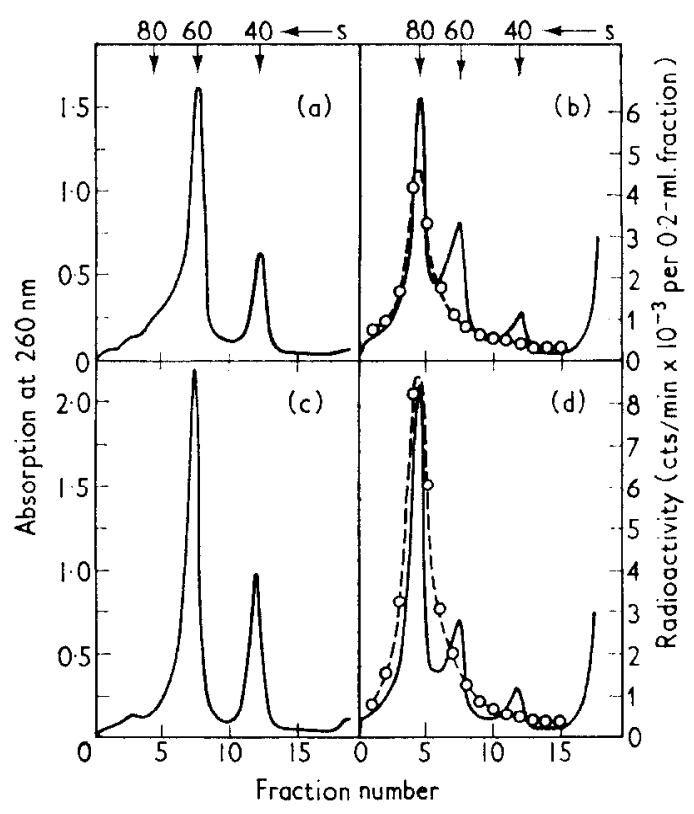

FrG. 10. High salt sucrose gradient analyses $(0.3 \mathrm{~m}-\mathrm{KCl}, 0.003 \mathrm{M}$-magnesium acetate. $0 \cdot 02 \mathrm{M}$ Tris- $\mathrm{HCl} \mathrm{pH} \mathrm{7.5)}$ of in vivo $80 \mathrm{~s}$ ribosomes ((a) and (b)) and polysome-derived $80 \mathrm{~s}$ ribosomes ((c) and (d)) before ((a) and (b)) and after ((b) and (d)) incubation in a complete polyphenylalanine synthesizing system. Reaction mixtures similar to those described in Fig. 9 were incubated at $25^{\circ} \mathrm{C}$ for $60 \mathrm{~min}$. 
polypeptide synthesis of $80 \mathrm{~s}$ ribosomes isolated from fresh tissue homogenates with those derived from polysomes after in vitro chain termination. The experiment shown in Figure 9 compares the time dependence at $33^{\circ} \mathrm{C}$ of polyphenylalanine synthesis by in vivo and polysome-derived $80 \mathrm{~s}$ ribosomes. The kinetics are very similar, but polysome-derived $80 \mathrm{~s}$ ribosomes incorporate 1.6 to 1.7 times more phenylalanine than in vivo $80 \mathrm{~s}$ particles. Figure 10 shows the sucrose gradient analysis in high salt of a similar experiment, but using different preparations of in vivo and polysome-derived $80 \mathrm{~s}$ ribosomes. Only about $40 \%$ of the $60 \mathrm{~s}$ and $40 \mathrm{~s}$ subunits present in the in vivo $80 \mathrm{~s}$ preparation participate in polyphenylalanine synthesis compared to about $65 \%$ of those from polysome-derived $80 \mathrm{~s}$ couples. 'I'hese results confirm and extend observations reported by Bishop (1965).

Further investigations are needed to understand fully and expand some of the implications of our data. More detailed physical, chemical and functional studies of the in vivo $80 \mathrm{~s}$ particles should clarify the nature and cause of their low activity in polypeptide synthesis. And, investigation of initiation with natural messenger is required in order to determine whether subunits of $80 \mathrm{~s}$ couples participate in the natural ribosome-mRNA binding reaction.

This work was supported by a research grant (GB-7259) from the National Science Foundation and in part by an Institutional Research Grant (IN-40-H) from the American Cancer Society to the University of Michigan Cancer Institute.

\section{REFERENCES}

Baliga, B. S., Pronczuk, A. W. \& Munro, H. N. (1968). J. Mol. Biol. 34, 199.

Bishop, J. O. (1965). Nature, 208, 361.

Bishop, J. O. (1966). Biochim. biophys. Acta, 119, 130.

Colombo, B., Vesco, C. \& Baglioni, C. (1968). Proc. Nat. Acad. Sci., Wash. 61, 651.

Falvey, A. K. \& Staehelin, T. (1970). J. Mol. Biol. 53, 1.

Ghosh, H. P. \& Khorana, H. G. (1967). Proc. Nat. Acad. Sci., Wash. 58, 2455.

Girard, M., Latham, H., Penman, S. \& Darnell, J. E. (1965). J. Mol. Biol. 11, 187.

Grubmann, M. J. \& Nakada, D. (1969). Nature, 223, 1242.

Guthrie, C. \& Nomura, M. (1968). Nature, 219, 232.

Hogan, B. L. M. \& Korner, A. (1968a). Biochim. biophys. Acta. 169, 129.

Hogan, B. L. M. \& Korner, A. (1968b). Biochim. biophys. Acta, 169, 139.

Kaempfer, R. O. (1968). Proc. Nat. Acad. Sci., Wash. 61, 106.

Kaempfer, R. O. (1969). Nature, 222, 950.

Kaempfer, R. O., Meselson, M. \& Raskas, H. J. (1968). J. Mol. Biol. 31, 277.

Mangiarotti, G. \& Schlessinger, D. (1966). J. Mol. Biol. 20, 123.

Nomura, M. \& Lowry, C. V. (1967). Proc. Nat. Acad. Sci., Wash. 58, 946.

Nomura, M., Lowry, C. V. \& Guthrie, C. (1967). Proc. Nat. Acad. Sci., Wash. 58, 1487.

Pestka, S. \& Nirenberg, M. (1966). J. Mol. Biol. $21,145$.

Staehelin, T., Verney, E. \& Sidransky, H. (1967). Biochim. biophys. Acta, 145, 105.

Subramanian, A. R., Ron, F. Z. \& Davis, B. D. (1968). Proc. Nat. Acad. Sci., Wash. 61, 761. 